\title{
DIAGNÓSTICO AMBIENTAL DE UM FRAGMENTO DE MATA CILIAR DO RIO
} TOCANTINS

Suza Teles Santos Lourenço ${ }^{1}$, Sâmila Serpa da Silva Mafra ${ }^{1}$, Odali Moura Gusmão ${ }^{1}$, Virgílio Lourenço Silva Neto ${ }^{2}$, Priscila Bezerra de Souza ${ }^{3}$

1 Discente do Curso de Graduação em Ciências Biológicas da Universidade Federal do Tocantins-UFT, Campus de Gurupi

2 MSc em Ciência Florestais e Ambientais, Professor do Instituto Federal de Educação, Ciências e Tecnologia do Tocantins-IFTO, Campus Dianópolis. E-mail: virgilio.neto@ifto.edu.br

3 Professora adjunta III da Universidade Federal do Tocantins, Coordenadora do Curso de Graduação em Ciências Biológicas da UFT, Campus Gurupi

Recebido em: 03/10/2016 - Aprovado em: 21/11/2016 - Publicado em: 05/12/2016 DOI: 10.18677/EnciBio 2016B 111

Nos últimos anos, vem aumentando a ocupação em áreas de preservação permanentes às margens do rio Tocantins, dando origem a impactos ambientais que podem evoluir causando grandes danos ao meio natural. Portanto objetivou-se realizar um diagnóstico ambiental de um fragmento de área de preservação permanente à margem esquerda do Rio Tocantins, além de identificar danos ambientais na área estudada para quantificação dos impactos causados pela ação antrópica. Para o diagnóstico ambiental, realizaram-se observações in loco para levantamento dos principais impactos, utilizando-se um dispositivo móvel de sistema de posicionamento global (GPS) para delimitação da área pesquisada, identificação e enumeração dos impactos observados em campo foi aplicado um "check-list" e posterior caracterização das ações impactantes, as quais só podem ser mitigadas com intervenção antrópica. Os impactos ambientais mais relevantes são decorrentes do desmatamento, que proporcionou a exposição do solo, desencadeando o processo erosivo. Também foram observadas deposições inadequadas de resíduos sólidos e construção inadequada de edificações na APP. Embora a exposição do solo tenha provocado erosão de grande magnitude, a maior parte dos impactos ambientais é considerada moderada, reversível e de média magnitude.

PALAVRAS-CHAVE: ação antrópica, área de preservação permanente, Cerrado

\section{ENVIRONMENTAL DIAGNOSIS OF A RIPARIAN VEGETATION SHRED THE LEFT BORDER OF THE TOCANTINS RIVER}

\begin{abstract}
In recent years, has increased the occupation in permanent preservation areas of the Tocantins river, giving rise to environmental impacts that may develop causing major damage to the natural environment. In this context, the objective was to make an environmental diagnosis of a fragment of permanent preservation area on the left bank of the Tocantins River, in addition to identifying environmental damage in the area studied to quantify the impacts caused by human action. For environmental
\end{abstract}


assessment, there were field observations for survey of the main impacts, using a mobile device global positioning system (GPS) to delimitation of the area searched for identification and enumeration of the impacts observed in the field was applied a "check-list" and further characterization of impactful actions, which can only be mitigated by human intervention. The most significant environmental impacts are from deforestation, which provided the exposure of soil, triggering erosion. Also observed were inadequate deposition of solid waste and inadequate construction of buildings in APP. Although soil erosion exposure has caused great magnitude, most of environmental impacts is considered moderate, reversible and medium magnitude.

KEYWORDS: anthropic action, permanent preservation area, savannah

\section{INTRODUÇÃO}

A grande biodiversidade registrada no Cerrado deve-se, em parte, ao mosaico de formações vegetais que constituem o Bioma Cerrado, sendo o mesmo classificado em três tipos vegetacionais sendo as formações florestais: Mata de Galeria, Mata Ciliar, Mata Seca e Cerradão, as formações savânicas: Vereda, Palmeiral, Parque Cerrado e Cerrado sensu stricto e as formações campestres composta por: Campo Limpo, Campo Sujo e Campo Rupestre, totalizando assim 11 tipos fisionômicos (EITEN, 1977; RIBEIRO \& WALTER, 2008).

As transformações ocorridas neste ecossistema também trouxeram grandes danos ambientais - fragmentação de hábitats, extinção da biodiversidade, invasão de espécies exóticas, erosão dos solos, poluição de aquíferos, degradação de ecossistemas, alterações nos regimes de queimadas, desequilíbrios no ciclo do carbono e possivelmente modificações climáticas regionais (KLINK \& MACHADO, 2005).

Ao analisar dois períodos distintos, sendo o primeiro entre 1949 a 1968 e o segundo entre 1979 a 1998, COSTA et al. (2003), afirmam que os efeitos da modificação da cobertura do solo provocaram um aumento na precipitação da ordem de $0,13 \mathrm{~mm} \mathrm{dia}^{-1}\left(47 \mathrm{~mm} \mathrm{ano}^{-1}\right.$, ou $3 \%$ ), um aumento da descarga de $0,24 \mathrm{~mm} \mathrm{dia}{ }^{-1}$ (88 $\mathrm{mm}^{2} \mathrm{ano}^{-1}$, ou 24\%). Segundo o autor, Em 1998, 49\% da bacia do rio Tocantins tinha sido convertida em áreas de plantio e pastagens, aumentando a descarga do rio em $24 \%$.

Segundo FREITAS et al. (2013), as áreas de preservação permanentes têm função ambiental de preservar os recursos naturais, a biodiversidade, fauna e flora, o solo e a segurança do bem-estar das populações humanas. O Código Florestal Brasileiro, estabelecido por meio da Lei 4.771 de 1965 e modificado posteriormente por outros instrumentos legais, como a Lei 7.754, de 14 de abril de 1989, a Medida Provisória no 2.166-67, de 24 de agosto de 2001, ambas revogadas pela Lei $\mathrm{n}^{\circ}$ 12.651, de 25 de maio de 2012, tem como principal prerrogativa a conciliação da preservação ambiental e do manejo sustentável dos recursos naturais com o uso e ocupação do solo pelo homem. Dentre o conjunto de medidas protecionistas contidas no Código Florestal, destacam-se as APPs e as áreas de Reserva Legal $(R L)$, as quais estabelecem normas para que as atividades de produção agropecuária possam ser conduzidas resguardando-se a conservação da biodiversidade e a geração de serviços ambientais (BRANCALION \& RODRIGUES, 2010).

A Lei 12.651/12 compreende por APP: área protegida, coberta ou não por vegetação nativa, com a função ambiental de preservar os recursos hídricos, a paisagem, a estabilidade geológica e a biodiversidade, proteger o solo e assegurar 0 bem-estar das populações humanas (BRASIL, 2012). Segundo GIUNTI et al. (2014), 
com essas recentes modificações ocorridas na Legislação Ambiental, há certa insegurança técnica e jurídica sobre os principais procedimentos a serem adotados para uma efetiva adequação e, com isso, em muitos casos, há uma suspensão nos processos de ajuste por parte das propriedades, o que pode comprometer a recuperação ambiental da área.

Conforme AZEVEDO \& OLIVEIRA (2014), além de instituir algumas alterações nas situações classificadas como APPs, o novo Código trouxe modificações no manejo e no regime de proteção desses espaços territoriais especialmente protegidos. O objetivo do instituto jurídico "área preservação permanente" é autoexplicativo: preservar determinadas áreas de modo permanente. Entretanto, existem situações em que pode ser autorizada a intervenção em APPs, nas hipóteses de utilidade pública, de interesse social ou de baixo impacto ambiental previstas na Lei no 12.651 , de 25 de maio de 2012.

NERES et al. (2015), afirmam que para análise do nível de impacto, pode-se utilizar o diagnóstico ambiental, baseado na observação, descrição e análise dos aspectos ambientais da área de estudo em determinado momento, considerando componentes do meio físico, biológico e humano e de suas interações. Neste sentido, estudos realizados no intuito de diagnosticar impactos ambientais em diferentes escalas surgiram em função da importância de se compreender a realidade atual de um determinado lugar e dos fatores internos e externos que podem facilitar ou dificultar o desenvolvimento local, que contribui de igual modo para a criação de informações do local, que comparadas, somadas e interpoladas, ressaltam as principais características e fornecem indícios da dinâmica da região, sua importância reside na apresentação de uma visão analítica do fenômeno em estudo em determinado espaço, nas variáveis que determinam e das relações mais importantes (RODRIGUES et al., 2014).

BAILLY et al. (2012), realizaram um diagnóstico ambiental e impactos sobre a vegetação ciliar da microbacia do córrego da Ponte, Área de proteção ambiental do rio Iguatemi, MS, em que verificaram a ocupação urbana desordenada às margens do córrego da Ponte, por meio do avanço da população em direção ao corpo hídrico, sendo o principal problema diagnosticado pelos autores, o despejo da galeria pluvial, ausência de mata ciliar na nascente, pisoteio do gado e ocorrência de erosões.

FREITAG et al. (2014), pesquisaram sobre diagnóstico ambiental e recomendações para recuperação de voçorocas no córrego Cabeceira Grande, em Campo Verde-MT, após verificarem o avanço do processo erosivo que se desenvolveu na região a partir da década de 90, ocasionado por diversos fatores como o uso e ocupação do solo e remoção da vegetação nativa. Este processo foi intensificado principalmente pela descarga de parte da água pluvial de drenagem da cidade de Campo Verde. Segundo estes autores, a evolução do processo erosivo está diretamente relacionada à presença ou ausência de cobertura vegetal.

FREITAS et al. (2013), avaliaram indicadores ambientais para APPs na Bacia do Rio Jundiaí-Mirim, que pertence à Unidade de Gerenciamento de Recursos Hídricos do Estado de São Paulo, afirmando que o uso agrícola expõe o solo frequentemente à ação erosiva da chuva e do vento como, por exemplo, o preparo do solo para plantio das culturas. Este manejo impede a regeneração natural e a formação de floresta nativa.

No Estado do Tocantins, RODRIGUES et al. (2014), fizeram um diagnóstico ambiental de um trecho da APP, às margens do córrego Pouso do Meio, em Gurupi$\mathrm{TO}$, onde verificaram vários problemas no que se refere ao corpo hídrico e às suas 
margens. Os autores afirmam que as condições de degradação dos corpos de água por assoreamento, ocorrência de erosões do solo, deposição de lixo e a ausência de mata ciliar obrigatória no trecho observado é preocupante.

OLIVEIRA et al. (2015), elaboraram propostas de recuperação para a nascente do córrego Mutuca, também no município de Gurupi-TO, após observarem o desmatamento, a presença de plantas exóticas, processo de assoreamento, erosão acelerada e formação de voçoroca. Tais propostas contemplam a construção de um conjunto de terraços projetados, segundo as condições locais, para controlar o início do processo erosivo próximo a nascente, isolar da área que deve ser recuperada com arame, a fim de impedir o acesso de animais e o acesso de pessoas, para evitar o risco de danos ao meio, reflorestamento heterogêneo utilizando espécies nativas do bioma Cerrado de áreas de nascentes e Matas Ciliares.

Neste mesmo município, FERREIRA et al. (2015) e NERES et al. (2015), também realizaram um diagnóstico ambiental do córrego Mutuca, onde verificaram a ocupação urbana desordenada, ausência da mata ciliar, sinais de processos erosivos e agricultura de subsistência familiar em suas margens, além da presença de animais mortos e disposição inadequada de resíduos sólidos. Estes estudos propuseram a realização de um plano para recuperação da área degradada, o isolamento da área e utilização de barreiras físicas para conter o assoreamento, a capina para controlar as espécies exóticas, auxiliando a regeneração natural em áreas que possuem resiliência nem como o plantio de mudas nativas.

SILVA NETO et al. (2016), fizeram caracterização dos aspectos ambientais na APP do Córrego Dois Irmãos em Gurupi-TO, onde observaram que 8,1 ha da APP está fortemente degradada, o que corresponde a um total de $50,6 \%$ no alto curso do córrego supracitado, com construções de áreas de lazer que invadem inclusive o leito do lago e edificações irregularmente construídas na área, que deveria ser destinada à preservação.

GONÇALVES et al. (2016), realizaram um diagnóstico ambiental e proposta de recuperação da APP, na fazenda Santa Juliana em Cariri do Tocantins, verificando retirada da vegetação ripária, exposição e compactação do solo diagnosticado por inferência e assoreamento do corpo d'água. Os autores propuseram retirar espécies herbáceas exóticas invasoras, nos lugares onde é possível, induzir a germinação do banco de sementes no solo e conduzir a regeneração natural, nos locais onde as condições não permitem, realizar o plantio de espécies florestais nativas e/ou frutíferas, diminuindo também os efeitos negativos da exposição, compactação do solo e do assoreamento.

Entretanto estudos sobre diagnóstico ambiental e impactos sobre a vegetação ciliar do Rio Tocantins ainda são escassos ou incipientes promovendo assim uma lacuna de informações técnicas e científicas. Portanto, objetivou-se realizar um diagnóstico ambiental de um fragmento de APP do Rio Tocantins, além de identificar danos ambientais encontrados na área de estudo para quantificação dos impactos causados pela ação antrópica.

\section{MATERIAL E MÉTODOS}

A região pesquisada encontra-se próximo aos limites entre os municípios de Gurupi e Peixe-TO, à margem esquerda do Rio Tocantins, perfazendo $555 \mathrm{~m}$ de perímetro e $14.924,7 \mathrm{~m}^{2}$ de área observada. O diagnóstico foi realizado nos $100 \mathrm{~m}$ imediatamente a partir da margem. A localização da área considerada neste estudo 


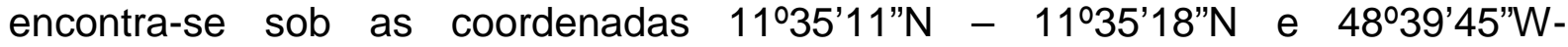
4840’09”W (Figura 1).

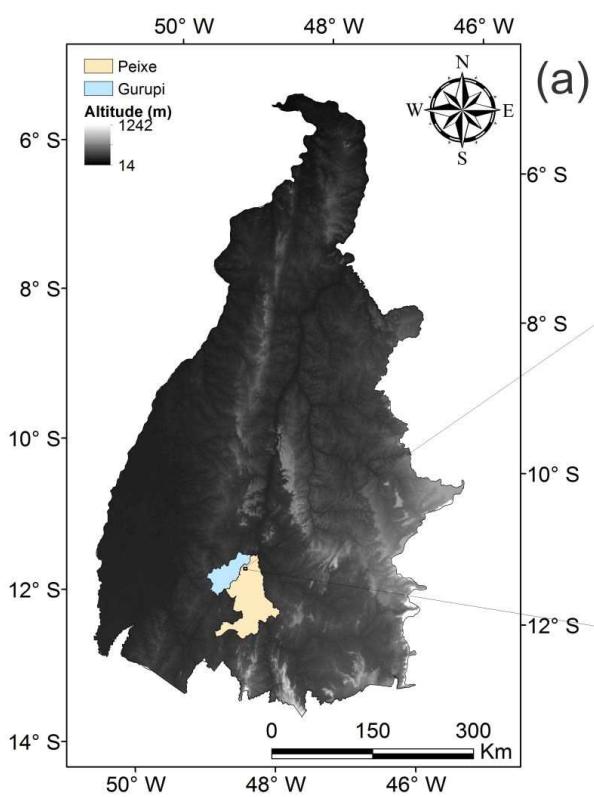

(b)

FIGURA 1 - (a) Modelo digital de elevação ASTER para o Estado do Tocantins com Datum Horizontal SAD 69 (autores, 2016) e (b) localização da Área de estudo - Margem esquerda do Rio Tocantins, Município de Peixe-TO (Google Earth, 2016).

Conforme a Lei 12.651 de 25 de maio de 2012, citada por SILVA NETO et al. (2016), as faixas marginais de qualquer curso d'água natural perene e intermitente, excluídos os efêmeros, desde a borda da calha do leito regular, em largura mínima de: a) 30 (trinta) metros, para os cursos d'água de menos de 10 (dez) metros de largura; b) 50 (cinquenta) metros, para os cursos d'água que tenham de 10 (dez) a 50 (cinquenta) metros de largura; c) 100 (cem) metros, para os cursos d'água que tenham de 50 (cinquenta) a 200 (duzentos) metros de largura; d) 200 (duzentos) metros, para os cursos d'água que tenham de 200 (duzentos) a 600 (seiscentos) metros de largura; e) 500 (quinhentos) metros, para os cursos d'água que tenham largura superior a 600 (seiscentos) metros.

Para o diagnóstico ambiental, foram realizadas visitas de campo, para levantamento dos principais impactos na área, utilizando-se um GPS e o software ArcGis ${ }^{\circledR} 10.2$ para delimitação da área pesquisada, para elencar os aspectos ambientais observados in loco, foi aplicado um "check-list" conforme SANCHEZ (2008). A medida das distâncias foi realizada por meio da utilização do GPS e do software ArcGis ${ }^{\circledR}$ 10.2. Para análise das ações impactantes foi utilizada como referência a Resolução do CONAMA nํ0 001/86, com os parâmetros descritos por RODRIGUES et al. (2014).

A identificação dos impactos ambientais realizadas por meio de visitas de campo, considerando os aspectos a serem avaliados descritos no quadro 1. Em seguida, elaborou-se a interação, possibilitando determinar ações impactantes indiretas, a partir de relações entre os indicadores, provocados por uma ação impactante direta, conforme descrito por NEREZ et al. (2015). 
QUADRO 1 - Caracterização dos impactos ambientais conforme resolução do CONAMA no 001/86

\begin{tabular}{|c|c|c|c|}
\hline Aspecto & PA & $\mathbf{S}$ & Descrição \\
\hline Efeito & $\begin{array}{l}\text { Negativo } \\
\text { Positivo }\end{array}$ & $\begin{array}{l}\mathbf{N} \\
\mathbf{P}\end{array}$ & $\begin{array}{l}\text { Dano à qualidade de um fator ou parâmetro ambiental. } \\
\text { Melhoria de um fator ou parâmetro ambiental. }\end{array}$ \\
\hline Ordem & $\begin{array}{l}\text { Nulo } \\
\text { Direto } \\
\text { Indireto }\end{array}$ & $\begin{array}{l}0 \\
\text { D } \\
\text { I }\end{array}$ & $\begin{array}{l}\text { Fator cujos efeitos inexistem. } \\
\text { Simples relação de causa e efeito. } \\
\text { Ação secundária, ou quando é parte de uma cadeia de } \\
\text { reações. }\end{array}$ \\
\hline Tempo & $\begin{array}{l}\text { Cíclico } \\
\text { Curto } \\
\text { Médio } \\
\text { Longo }\end{array}$ & $\begin{array}{l}\text { Ci } \\
C \\
M \\
L\end{array}$ & $\begin{array}{l}\text { Efeitos se fazem sentir de forma cíclica ou periódica. } \\
\text { A ação permanece num curto espaço de Tempo. } \\
\text { A ação pode ser cessada após um tempo. } \\
\text { O efeito permanece após muito tempo após ter-se dado } \\
\text { à ação. }\end{array}$ \\
\hline Dinâmica & $\begin{array}{l}\text { Estratégico } \\
\text { Temporário } \\
\text { Permanente }\end{array}$ & $\begin{array}{l}\mathbf{E} \\
\mathbf{T} \\
\mathbf{P}\end{array}$ & $\begin{array}{l}\text { Efeito assume reflexo estadual ou nacional. } \\
\text { O efeito do impacto permanece por um determinado } \\
\text { tempo, após o qual depois desaparece. } \\
\text { Os efeitos não cessam de se manifestar num horizonte } \\
\text { temporal conhecido. }\end{array}$ \\
\hline Plástica & $\begin{array}{l}\text { Reversível } \\
\text { Irreversível }\end{array}$ & $\begin{array}{l}\mathbf{R} \\
\mathbf{I R}\end{array}$ & $\begin{array}{l}\text { O local pode voltar a ter a paisagem original. } \\
\text { Após a ação impactante, mesmo com medidas } \\
\text { mitigadoras, o local não volta a ter a paisagem original. }\end{array}$ \\
\hline Magnitude & $\begin{array}{l}\text { Pequena } \\
\text { Média } \\
\text { Grande }\end{array}$ & $\begin{array}{r}1-3 \\
4-6 \\
7-10\end{array}$ & $\begin{array}{l}\text { O meio permanece inalterado. } \\
\text { O meio apresenta uma leve alteração quanto à sua } \\
\text { paisagem, porém de forma inexpressiva. } \\
\text { A ação altera toda a paisagem. }\end{array}$ \\
\hline Espaço/Escala & $\begin{array}{l}\text { Local } \\
\text { Regional }\end{array}$ & $\begin{array}{l}\text { Lo } \\
\text { Re }\end{array}$ & $\begin{array}{l}\text { Afeta apenas a área local do empreendimento. } \\
\text { O efeito extrapola a área de implantação do } \\
\text { empreendimento. }\end{array}$ \\
\hline Frequência & $\begin{array}{l}\text { Baixa } \\
\text { Média } \\
\text { Alta }\end{array}$ & $\begin{array}{l}1 \\
2 \\
3\end{array}$ & $\begin{array}{l}\text { Sem danos ou com danos mínimos ao meio ambiente. } \\
\text { Leve alteração quanto à sua paisagem, porém de forma } \\
\text { inexpressiva. } \\
\text { A ação altera toda a paisagem. }\end{array}$ \\
\hline Significância & $\begin{array}{c}\text { Não } \\
\text { Significativa } \\
\text { Moderada } \\
\text { Significativa }\end{array}$ & $7-9$ & $\begin{array}{l}\text { Não altera a qualidade de vida do meio ou do homem. } \\
\text { A área lesionada pela ação, quando negativa, pode ser } \\
\text { recuperada e quando positiva, apresenta uma melhoria } \\
\text { razoável na qualidade de vida. } \\
\text { Apresenta uma significativa evolução benéfica ao meio } \\
\text { ambiente, quando positiva, e uma perda na qualidade } \\
\text { de vida quando negativa. }\end{array}$ \\
\hline
\end{tabular}

PA = Parâmetro de Avaliação; S = Símbolo; Fonte: (Adaptado de RODRIGUES et al., 2015). 


\section{RESULTADOS E DISCUSSÃO}

O desmatamento foi o principal impacto registrado na área de observação, em um perímetro muito próximo da margem do rio, com distância em média de $50 \mathrm{~m}$ das ocupações. NEREZ et al. (2015), afirmam que a retirada da vegetação, ação impactante direta, provoca efeitos negativos para o solo, para a água e para a fauna. Ainda segundo os autores, com desmatamento, o solo fica exposto e suscetível à erosão, tendo como principal consequência a perda de solo e redução da serapilheira.

As ações impactantes observadas na área estudo são descritas e analisadas No quadro 2: retirada de vegetação nativa (desmatamento), erosão do solo, assoreamento, contaminação do rio e diminuição da biodiversidade da fauna e deposição inadequada de resíduos sólidos (Quadro 2).

QUADRO 2- Avaliação dos parâmetros ambientais observados no fragmento da APP à margem esquerda do Rio Tocantins (Peixe-TO).

\begin{tabular}{|c|c|c|c|c|c|c|c|c|c|c|}
\hline Ação Impactante & Impacto & $\frac{0}{\frac{0}{d}}$ & $\begin{array}{l}\text { ह } \\
\text { के } \\
\text { ठे }\end{array}$ & 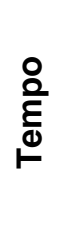 & 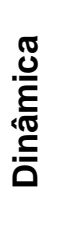 & $\frac{\pi}{\frac{\pi}{\pi}}$ & 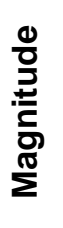 & 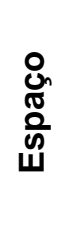 & 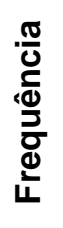 & 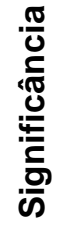 \\
\hline Desmatamento & $\begin{array}{l}\text { Redução da umidade } \\
\text { atmosférica; } \\
\text { desequilíbrio no } \\
\text { ecossistema. }\end{array}$ & $\mathrm{N}$ & $\mathrm{D}$ & L & $P$ & $\mathrm{R}$ & 5 & Lo & 2 & 4 \\
\hline $\begin{array}{l}\text { Exposição do } \\
\text { Solo }\end{array}$ & Erosão do solo & $\mathrm{N}$ & 1 & $\mathrm{~L}$ & $P$ & $\mathrm{R}$ & 7 & Lo & 2 & 6 \\
\hline $\begin{array}{l}\text { Assoreamento } \\
\text { dos corpos } \\
\text { hídricos }\end{array}$ & $\begin{array}{l}\text { Deposição de } \\
\text { partículas sólidas no } \\
\text { Rio Tocantins }\end{array}$ & $\mathrm{N}$ & 1 & L & $P$ & $\mathrm{R}$ & 4 & Lo & 3 & 6 \\
\hline $\begin{array}{c}\text { Construções } \\
\text { irregulares na } \\
\text { área da APP } \\
\end{array}$ & $\begin{array}{l}\text { Perda da vegetação } \\
\text { ciliar, desestruturação } \\
\text { do ecossistema ripário }\end{array}$ & $\mathrm{N}$ & D & L & $P$ & $\mathrm{R}$ & 6 & Lo & 2 & 5 \\
\hline $\begin{array}{l}\text { Deposição } \\
\text { inadequada de } \\
\text { resíduos sólidos }\end{array}$ & Contaminação do solo & $\mathrm{N}$ & D & M & $P$ & $\mathrm{R}$ & 4 & Lo & 2 & 5 \\
\hline & & & & & & & & & & \\
\hline
\end{tabular}

$\mathrm{N}$ = Negativo; $\mathrm{D}=$ Direto; $\mathrm{I}=$ Indireto; $\mathrm{L}$ = Longo; $\mathrm{M}$ = Moderado; $\mathrm{R}$ = Reversível; $\mathrm{Lo}=$ Local (Fonte: Autores, adaptado de Sanches, 2008)

A Figura 2 a e b mostram áreas em que a cobertura vegetal foi retirada, destacando-se que este foi o principal impacto ambiental observado neste estudo. 

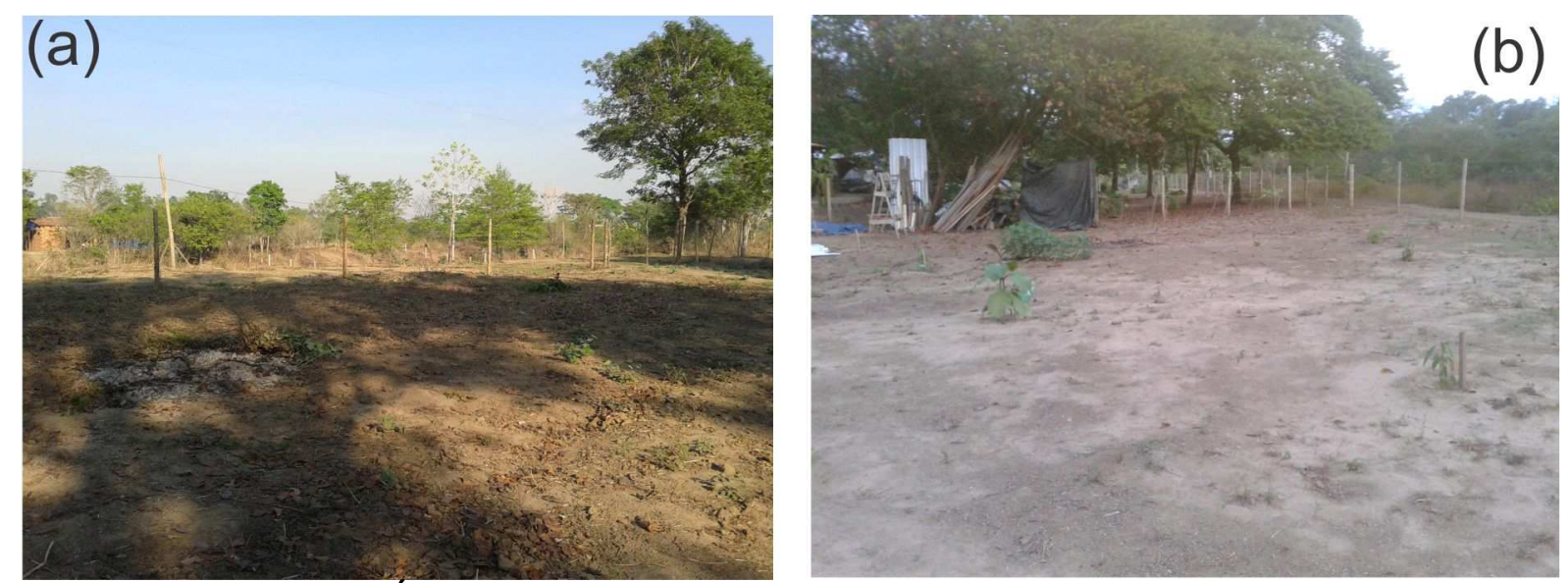

FIGURA 2 - (a e b) Áreas desmatada. (Fonte: Autores, 2016).

RODRIGUES et al., (2014), constataram em seu trabalho que a retirada de cobertura vegetal do Córrego Pouso do Meio em Gurupi-TO, podem ser minimizados com medidas mitigadoras ou compensatórias para recuperação dessa área degradada, tais como: restauração da flora local com plantio de mudas e construção de viveiros de espécies nativas.

A Figura 3 apresenta o impacto caracterizado pela exposição do solo, gerando erosão do tipo voçoroca, com grande volume de solo perdido, transportado pelo vento e pela água da chuva para o leito do rio Tocantins, iniciando o processo de assoreamento local. Deve-se enfatizar que as Figuras 2 (a e b) e 3 (a e b) foram registradas a uma distância de menos de $70 \mathrm{~m}$ da margem esquerda do Rio Tocantins.
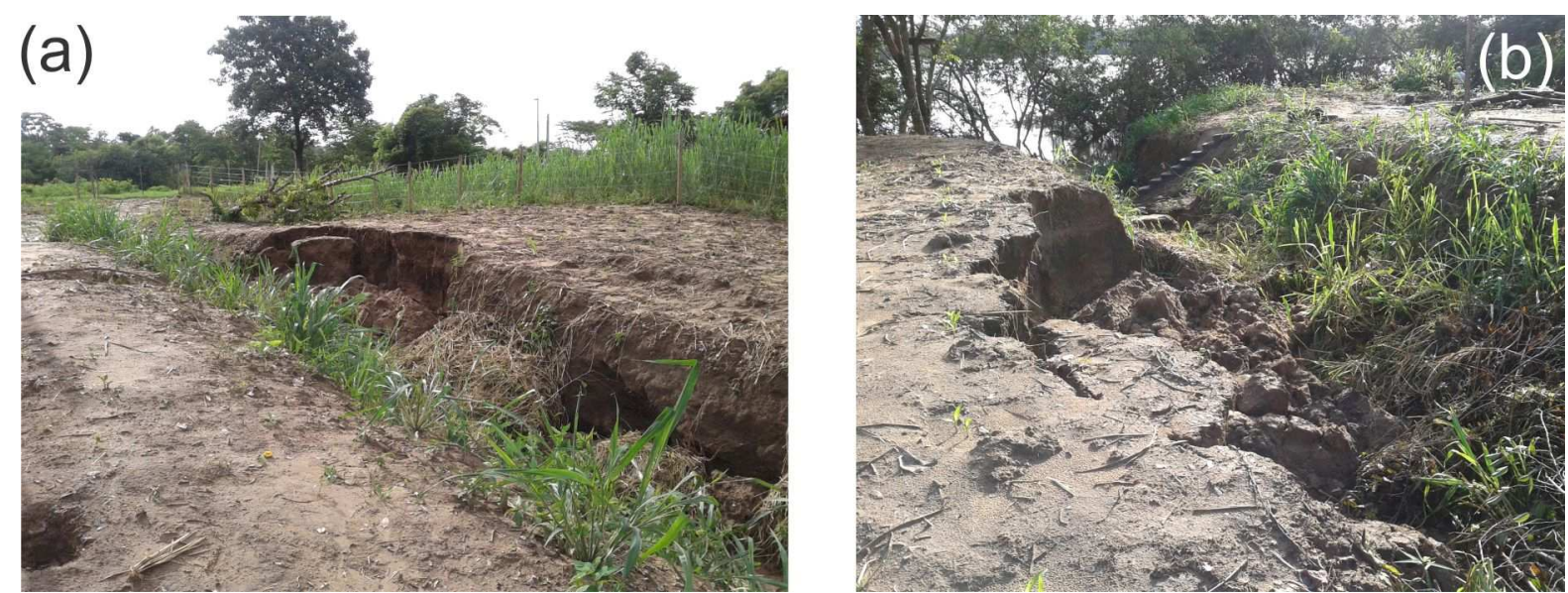

FIGURA 3 - (a e b) Erosão do solo, provocada pela exposição em função desmatamento (Fonte: Autores, 2016).

No Diagnóstico da APP do córrego Mutuca, em Gurupi-TO, NERES et al. (2015) identificaram erosão do solo do tipo voçoroca, provocada pelo transporte do solo, por meio fluvial e eólico, devido à exposição do solo. Os autores afirmam que a retirada da vegetação expõe a fragilidade do solo, como consequência, todo o processo acaba sendo alterado com perda da qualidade e de massa do solo, ocasionando assim a erosão.

Constatou-se com as visitas de campo que há relação entre o desmatamento e o processo erosivo in loco, entretanto quando se observava ENCICLOPÉDIA BIOSFERA, Centro Científico Conhecer - Goiânia, v.13 n.24; p.1196 2016 
presença de serapilheira e cobertura vegetal (vegetação herbácea, subarbustiva e arbustiva) as mesmas atuavam como uma barreira física contra o processo erosivo, ou seja, a cobertura vegetal e a serapilheira auxilia no processo de sustentação da estrutura do solo, evitando assim a perda de sedimentos pelos agentes intempéricos principalmente vento e água da chuva.

OCHIAI \& NAKAMURA (2004), afirmam que a camada serapilheira cria uma barreira física que fornece resistência mecânica ao escoamento superficial gerado, reduzindo assim a velocidade do fluxo. Consequentemente, favorece a infiltração, por conseguinte quando há ocorrência do escoamento superficial da água a barreira física formada pela camada serapilheira reduz o volume de solo erodido.

Uma verificação importante realizada neste estudo foi a forma como as propriedades foram divididas, resultado um loteamento realizado na Fazenda Santo Antônio, município de Peixe-TO, em terrenos com 28,5m x 1.965m (5,6 ha), perpendicularmente ao Rio Tocantins, principalmente nos $200 \mathrm{~m}$ a partir do curso d'água, onde se diagnosticou os impactos inerentes da retirada da cobertura vegetal. Na tentativa de conter o processo erosivo, proprietários +utilizam pneus, para utilização como escada de acesso ao rio, entretanto, percebe-se na verdade a deposição inadequada deste tipo de resíduo.
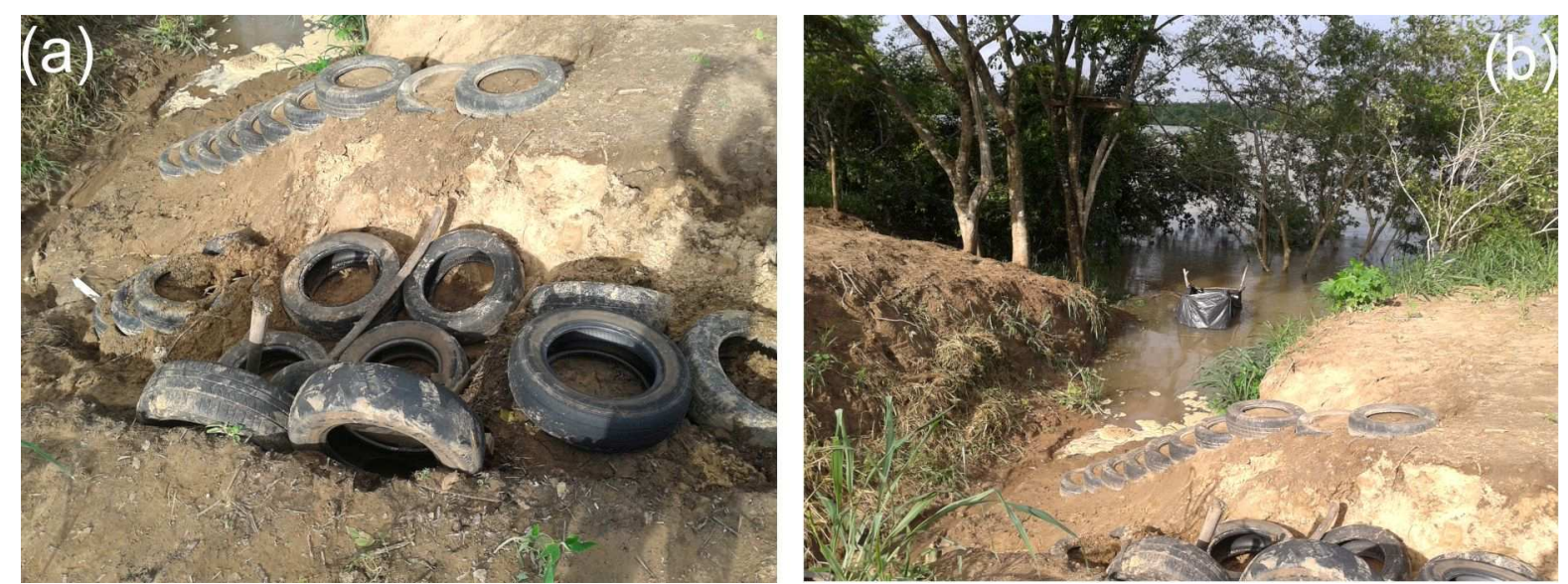

FIGURA 4 - (a e b) Deposição inadequada de pneus na tentativa de conter a erosão e de dar acesso ao rio como escadas (Fonte: autores, 2016).

RODRIGUES et al. (2014), em estudo da APP do córrego Pouso do Meio, afirmam que erosões marcantes são responsáveis por causar impactos ambientais no trecho observado, sendo que o enfoque ambiental das erosões se refere aos danos causados ao meio ambiente como um todo, abrangendo e prejudicando além do solo, a água, a fauna e a vegetação. Além deste tipo de resíduo (pneus), que possui tempo indeterminado de decomposição na natureza é possível perceber ainda a contaminação do solo e rio com dejetos orgânicos gerados por banheiros instalados de forma inadequada (Figura $2 b$ e $4 b$ ).

Outra ação impactante é a construção irregular de imóveis, em virtude da localização a 56m a partir da margem do rio, segundo o Novo Código Florestal, citado por OLIVEIRA et al. (2015) e SILVA-NETO et al. (2016), a construção deveria estar fora da faixa dos $200 \mathrm{~m}$ da APP, uma vez que neste trecho a largura do Rio Tocantins varia entre $570 \mathrm{~m}$ a $590 \mathrm{~m}$. Segundo SILVA-NETO et al. (2016), a destruição da mata ciliar pelo avanço das edificações não obedece às determinações do Novo Código Florestal Brasileiro, que estabelece uma distância mínima de preservação em relação aos córregos e nascentes. 
PEREIRA et al., (2014), pesquisando sobre a evolução espaço-temporal do uso e cobertura da terra do Ribeirão Piancó em Anápolis-GO, afirmam que a classe vegetação natural, que em 1989 cobria 10,9\% da área da bacia e em 2007 passou para $10,6 \%$, apresentou uma redução de área no período estudado. Esta classe abrange a vegetação de cerrado com fragmentos florestais ainda existentes na região incluindo as matas ciliares que se encontram em diversos estágios de crescimento. Essas áreas vêm sendo reduzidas devido à ocupação para expansão da pecuária e culturas. Contudo, constata-se que a fiscalização pelos órgãos competentes ainda é insuficiente, havendo muitas vezes o corte seletivo para madeira entre outras atividades predatórias. Esta falta de fiscalização nas APPs às margens do Rio Tocantins também contribui para a retirada da vegetação nativa da região.

A Figura 5 representa a interação entre os impactos ambientais descritos neste estudo, em um fragmento de APP à margem esquerda do Rio Tocantins. Observa-se que os impactos tiveram início com a retirada da vegetação nativa. Considerando RODRIGUES (2002) citado por KLINK \& MACHADO (2005), a degradação provocada pela exposição do solo e dos ecossistemas nativos e a dispersão de espécies exóticas são as maiores e mais amplas ameaças à biodiversidade. A partir de um manejo deficiente do solo, a erosão pode ser alta, a perda da camada superficial do solo é, em média, de 25 ton/ha/ano, contribuindo assim para a perda e transporte de sedimentos para o leito do rio caracterizando assim o processo de assoreamento.

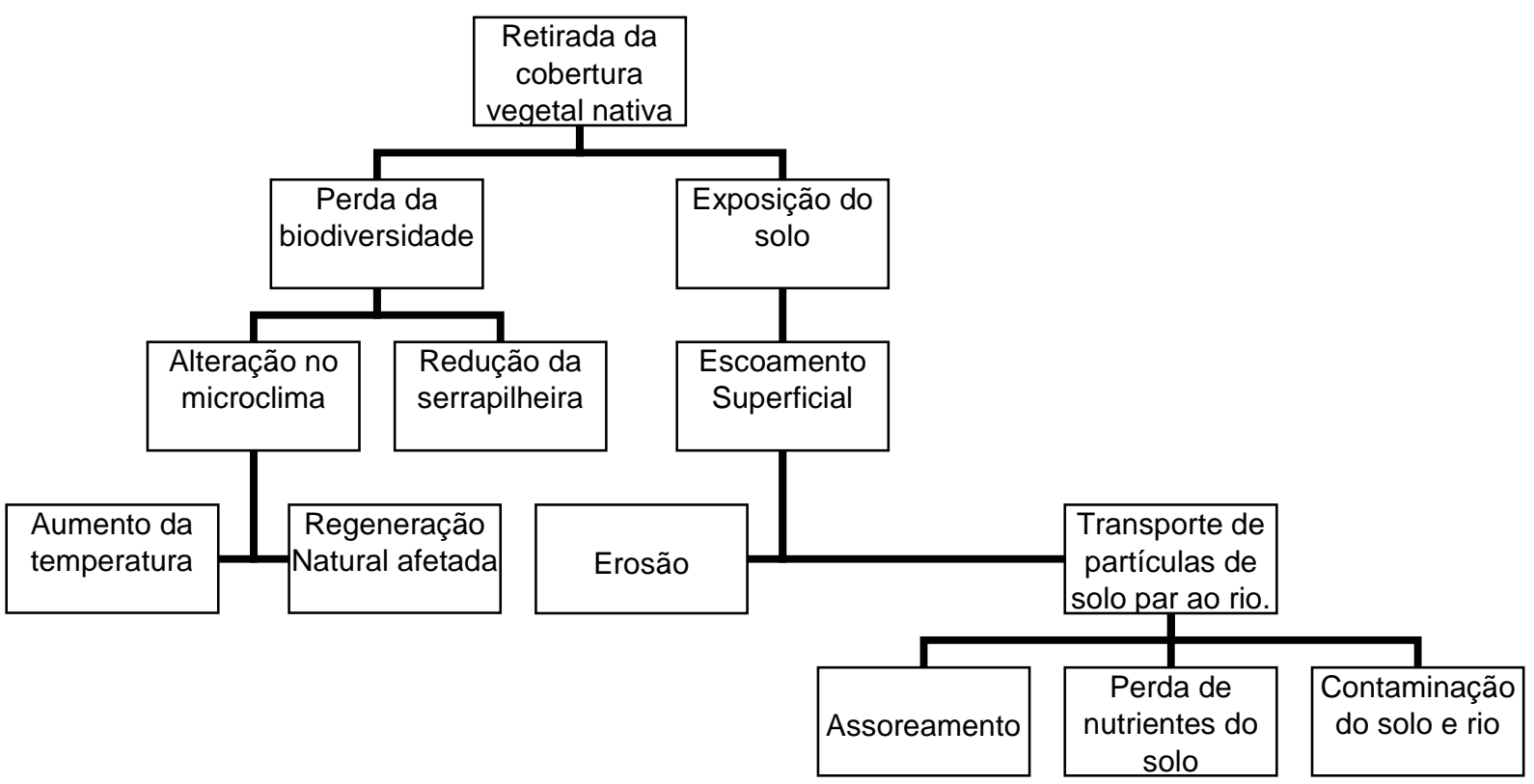

FIGURA 5 - Fluxograma dos impactos ambientais descritos neste estudo, em um fragmento de APP. Fonte: adaptado de NEREZ et al., (2015).

TSUJII et al. (2014), em estudos no sudoeste goiano, afirmam que a ação humana tem gerado às APP's impactos ambientais sérios principalmente a retirada da vegetação, provocando o risco de desaparecimento da vegetação nativa tanto perto como distante das áreas fluviais. $\mathrm{O}$ agronegócio instalado nesta região geográfica tem por tendência agravar este fato, caso dos setores sucroalcooleiro e de grãos, que concentraram os seus investimentos na região supracitada. 
No âmbito da retirada de vegetação ciliar, em estudos sobre ocupação de APP no ambiente urbano de Jataí-GO, SILVA NETO et al. (2013) afirmam que a porcentagem da ocupação das áreas de preservação permanentes do município em relação ao total de APP's da área urbana se apresenta reduzido, porém, é devida à grande quantidade de canais fluviais e consequentemente áreas de preservação permanentes no ambiente urbano. Quando as APP's ocupadas são observadas por curso d'água, as porcentagens se mostram maiores, evidenciando os cursos d'água com maior ocupação das APP's.

Neste estudo percebe-se que área entronizada possui resiliência considerando a maior parte das ações impactantes observadas, no entanto, para as erosões verificadas, somente com intervenção mecânica é possível reverter o processo. DOIDATO (2004) citado por NERES et al., (2015), afirma que as medidas mitigadoras têm por objetivo minimizar os impactos quando negativos e potencializálos quando positivo.

\section{CONCLUSÕES}

Foi possível observar que a área possui consideráveis impactos ambientais, dentre os quais só podem ser mitigados com intervenção antrópica.

Os impactos mais relevantes na área de estudo foram desmatamento, erosão do solo, deposição inadequada de resíduos sólidos, construções irregulares na faixa da APP e perda da biodiversidade.

Destes, a maior parte é considerada moderada, reversível e de média magnitude.

\section{REFERÊNCIAS}

AZEVEDO, R. E. S. D.; OLIVEIRA, V. P. V. D. Reflexos do novo Código Florestal nas Áreas de Preservação Permanente - APPs - urbanas. DEMA Desenvolvimento e Meio Ambiente, v. 29, n. 2, p. 71-91, 2014. Disponível em: < http://dx.doi.org/10.5380/dma.v29i0.32381 > doi: 10.5380/dma.v29i0.32381

BAILLY, D.; FERNANDES, C. A.; SILVA, V. F. B.; KASHIWAQUI, E. A. L.; DAMÁSIO, J. F.; WOLF, M. J.; RODRIGUES, M. C. Diagnóstico ambiental e impactos sobre a vegetação ciliar da microbacia do córrego da Ponte, Área de proteção ambiental do rio Iguatemi, MS. Revista em Agronegócio e Meio Ambiente, v. 5, n. 2, 2012. ISSN 2176-9168. Disponível em: < http://periodicos.unicesumar.edu.br/index.php/rama/article/viewFile/1680/1665 >

BRANCALION, P. H. S.; RODRIGUES, R. R. Implicações do cumprimento do Código Florestal vigente na redução de áreas agrícolas: um estudo de caso da produção canavieira no Estado de São Paulo/Redução de terras agrícolas devido ao cumprimento do Código Florestal atual: um estudo de caso da produção de cana no Estado de São Paulo. Biota Neotropica, v. 10, n. 4, p. 63, 2010. ISSN 1806-129X. Disponível em: http://www.biotaneotropica.org.br/v10n4/en/abstract?article+bn01010042010 >

BRASIL. 2012. Código Florestal. Lei n`12.651 de 25 de maio .

CONAMA. Brasília, 1986. Conselho Nacional de Meio Ambiente. Resolução no 001/1986. . 
COSTA, M. H.; BOTTA, A.; CARDILLE, J. A. Effects of large-scale changes in land cover on the discharge of the Tocantins River, Southeastern Amazonia. Journal of Hydrology, v. 283, n. 1, p. 206-217, 2003. ISSN 0022-1694. Disponível em: < dx.doi.org/10.1016/S0022-1694(03)00267-1 > doi: 10.1016/S0022-1694(03)00267-1

EITEN, G. 1977. Delimitação do conceito de cerrado. Arquivos do Jardim Botânico. n. 21, 125-134.

FERREIRA, R.; BATISTA, E.; SOUZA, P.; SOUZA, P.; SANTOS, A. Diagnóstico ambiental do córrego Mutuca, Gurupi-TO. Revista Verde de Agroecologia e Desenvolvimento Sustentável, v. 10, n. 4, p. 08-12, 2015. ISSN 1981-8203. Disponível em: < http://dx.doi.org/10.18378/rvads.v10i4.3146> Doi: 10.18378/rvads.v10i4.3146

FREITAG, R.; RIBEIRO, R. D. Q.; BONINI, I. Diagnóstico ambiental e recomendações para recuperação de uma área degradada por voçoroca no córrego cabeceira grande, Campo Verde-MT. Enciclopédia Biosfera, v. 10, n. 19, p. 20782090, 2014. Disponível em: < http://www.conhecer.org.br/enciclop/2014b/CIENCIAS\%20BIOLOGICAS/diagnostico $\% 20$ ambiental.pdf >

FREITAS, E. P.; DE MORAES, J. F.; PECHE FILHO, A.; STORINO, M. Indicadores ambientais para áreas de preservação permanente. Revista Brasileira de Engenharia Agrícola e Ambiental, Campina Grande, v. 17, n. 4, p. 443-449, 2013. Disponível em: < http://agriambi.com.br/revista/v17n04/v17n04a13.pdf >

GIUNTI, O. D.; DE SÁ, E. B. R.; DE OLIVEIRA, T. C.; SILVA, A. V. Análise e diagnóstico ambiental: adequações ao novo código florestal-um estudo de caso. Revista Agrogeoambiental, 2014. ISSN 2316-1817. Disponível em: < https://agrogeoambiental.ifsuldeminas.edu.br/index.php/Agrogeoambiental/article/vie wFile/746/587 >

GONÇALVES, D. S.; DE SOUZA, P. A.; DE OLIVEIRA, A. L.; MARTINS, T. S. Diagnóstico ambiental e proposta de plano de recuperação da APP, Fazenda Santa Juliana, Cariri do Tocantins. Nucleus, v. 13, n. 1, p. 261-276, 2016. ISSN 1982$2278 . \quad$ Disponível em:

http://www.nucleus.feituverava.com.br/index.php/nucleus/article/viewFile/1562/1983 $>$

KLINK, C. A.; MACHADO, R. B. A conservação do Cerrado brasileiro. Megadiversidade, v. 1, n. 1, p. 147-155, 2005. Disponível em: < http://www.nucleus.feituverava.com.br/index.php/nucleus/article/viewFile/1562/1983 > doi: $10.3738 / 1982.2278 .1562$

NERES, N. G. C.; SOUZA, P. A.; SANTOS, A. F. D.; GIONGO, M.; BARBOSA, L. N. L. Avaliação ambiental e indicação de medidas mitigadoras para a nascente do córrego mutuca, Gurupi-TO. Enciclopédia Biosfera, v. 11, n. 21, p. 2824-2834, 2015. 
http://www.conhecer.org.br/enciclop/2015b/multidisciplinar/avaliacao\%20ambiental\% $20 \mathrm{e} \% 20$ indicacao.pdf $>$

OCHIAI, H.; NAKAMURA, S. A função da camada de serapilheira no controle de erosão do solo. Pesquisas em conservação e recuperação ambiental no oeste paulista. São Paulo: Instituto Florestal/Secretaria de Estado do Meio Ambiente, p. 169-177, 2004. Disponível em: < http://iflorestal.sp.gov.br/files/2004/01//F-c11.pdf $>$

PEREIRA, L. S.; GONÇALVES, B. B.; SILVA NETO, C. D. M.; FERREIRA SANTOS, A. L. Evolução espaço-temporal do uso e cobertura da terra do Ribeirão Piancó em Anápolis-GO. Revista Mirante, v. 7, n. 1, 2014. ISSN 1981-4089. Disponível em: < http://www.revista.ueg.br/index.php/mirante/article/view/2741/1735 >

RODRIGUES, A. J.; PEREIRA, M. A.; MARTINS, I. C. D. M.; SOUZA., P. A. D. Diagnóstico Ambiental de um Trecho da Área de Preservação Permanente (APP), Margens do Córrego Pouso do Meio, em Gurupi-TO. Enciclopédia Biosfera, v. 11, n. 21, p. 3103-3113, $2015 . \quad$ Disponível em: < http:/www.conhecer.org.br/enciclop/2015b/multidisciplinar/Diagnostico\%20ambiental \%20de\%20um\%20trecho.pdf >

SILVA-NETO, C. D. M. E.; OKANO, S. F.; CARNEIRO, V. A.; GONÇALVES, B. B. Ocupação de áreas de preservação permanentes dos canais fluviais em ambiente urbano do município de Jataí-GO. Revista Percurso, v. 5, n. 2, p. 73-89, 2013. ISSN 2177-3300. Disponível em: < http://periodicos.uem.br/ojs/index.php/Percurso/article/view/21381/12143 >

SILVA-NETO, V. L.; FERREIRA JUNIOR, D. F.; SOUZA, P. A. D.; VIOLA, M. R. Diagnóstico Ambiental da Área de Preservação Permanente do Córrego Dois Irmãos em Gurupi-TO. Enciclopédia Biosfera, v. 13, n. 23, p. 470-486, 2016. Disponível em: < http://www.conhecer.org.br/enciclop/2016a/agrarias/diagnostico.pdf > Doi: 10.18677/Enciclopedia_Biosfera_2016_042

TSUJII, P. K.; RIBEIRO, A. C. C.; CARNEIRO, V. A.; NETO, C. D. M. E. S.; GONÇALVES, B. B. Uso e ocupação das áreas de preservação permanentes no sudoeste goiano. Revista de Geografia, v. 31, n. 3, p. 43-60, 2014. ISSN 22386211. Disponível em: http://www.revista.ufpe.br/revistageografia/index.php/revista/article/viewFile/776/576 $>$ 